\title{
Muito além da videoaula: diversificando as metodologias de ensino remoto de biologia
}

\author{
Beyond the video lesson: diversifying remote teaching methodologies in \\ biology
Más allá de la videoclase: diversificando las metodologías de enseñanza a distancia en biología

\author{
Amanda Santos Franco da Silva Abe (amandasantosfranco@gmail.com) \\ Colégio Pedro II, Rj.
}

Carla Christie Dibán Quijada (carlaquijadabio@hotmail.com)

Polo Educacional Sesc, $\mathrm{Rj}$.

Resumo: No contexto da pandemia de COVID-19 diversas escolas brasileiras admitiram o ensino remoto emergencial (ERE) como forma de manutenção e continuidade da educação escolar através, principalmente, de videoaulas disponibilizadas na internet. Considerando-se que muitos estudantes não possuem acesso a uma ampla rede de dados de internet, necessária para assistir videoaulas frequentemente, e compreendendo a necessidade de se diversificar as metodologias de ensino a fim de manter o engajamento discente durante o período de ERE, desenvolvemos o PowerPoint@ Dialogado, um material diferente das apresentações de PowerPoint ${ }^{\circledR}$ que os professores produzem cotidianamente para as aulas presenciais. Para construir este dispositivo, utilizamos ferramentas como o programa em si, gifs, animações, balões de fala, avatares das professoras, setas explicativas, além de personificar componentes da aula e usar linguagem coloquial. Como resultado verificou-se que os estudantes demonstraram preferência por essa metodologia para estudar durante o ERE, em detrimento de outras, e apresentaram resultados positivos nas avaliações.

Palavras-chave: PowerPoint ${ }^{\circledR}$ dialogado; Biologia; ensino remoto emergencial.

Abstract: In the context of the COVID-19 pandemic, several Brazilian schools have admitted emergency remote education (ERE) as a way of maintaining and continuing school education, mainly, through video classes available on the internet. Considering that many students do not have access to a large Internet data network, necessary to frequently watch video lessons, and understanding the need to diversify teaching methodologies in order to maintain student engagement during the ERE period, we developed the Dialogued PowerPoint ${ }^{\circledR}$, a different material from the PowerPoint ${ }^{\circledR}$ presentations that teachers produce routinely for regular, in person classes. To build this 
device, we used tools such as the software itself, gifs, animations, speech balloons, teacher's avatars, explanatory arrows, as well as to personifying components of the class and using colloquial language. As a result, it was found that students showed a preference for this methodology to study during ERE, to the detriment of others, and presented positive results in the evaluations.

Keywords: Dialogued PowerPoint $® ;$ Biology; emergency remote education.

Resumen: En el contexto de la pandemia de COVID-19, varias escuelas brasileñas admiten la enseñanza remota emergente (ERE) como forma de mantenimiento y continuidad de la educación escolar a través, principalmente, de videocápsulas disponibles en Internet. Teniendo en cuenta que muchos estudiantes no tienen acceso a una amplia red de datos de Internet, necesaria para ver las lecciones de vídeo con frecuencia, y entendiendo la necesidad de diversificar las metodologías de enseñanza para mantener el compromiso de los estudiantes durante el período de ERE, desarrollamos el PowerPoint ${ }^{\circledR}$ dialógico, un material diferente de las presentaciones de PowerPoint ${ }^{\circledR}$ que los profesores producen diariamente para las clases presenciales. Para construir este dispositivo, utilizamos herramientas como el propio programa, gifs, animaciones, globos de diálogo, avatares de las profesoras, flechas explicativas, además de personificar a los componentes de la clase y utilizar un lenguaje coloquial. Como resultado se comprobó que los alumnos mostraron preferencia por esta metodología para estudiar durante el ERE, sobre otras, y mostraron resultados positivos en las evaluaciones.

Palabras-clave: PowerPoint ${ }^{\circledR}$ dialógico; Biología; enseñanza de emergencias a distancia.

\section{INTRODUÇÃO}

O atual cenário mundial da pandemia de COVID-19 gerou a necessidade de isolamento social, que culminou no fechamento de diversos espaços, dentre eles, as escolas. A fim de dar continuidade aos processos de ensino-aprendizagem, considerando as demandas, desafios, dificuldades e potencialidades deste momento, algumas escolas passaram a promover o chamado ensino remoto emergencial (ERE) (HODGES et al., 2020). A Escola Sesc de Ensino Médio (ESEM), integrante do Pólo Educacional SESC, no Rio de Janeiro (RJ), foi uma delas.

Em março de 2020 a ESEM se reestruturou e se reorganizou para começar a oferecer ERE aos seus estudantes através de uma série de estratégias que incluíram a 
criação de uma plataforma Moodle ${ }^{\circledR}$ multifuncional. Este ambiente virtual passou a funcionar não só como repositório de materiais didáticos diversos produzidos pelos professores, mas também como um espaço de comunicação e interação aluno-professor, professor-aluno e aluno-aluno; fórum de discussões, banco de produções discentes, desenvolvimento colaborativo de projetos, avaliações, entre outros. Todas as metodologias, estratégias e avaliações que descreveremos neste trabalho foram depositadas e/ou praticadas nesta plataforma.

Quando se trata de ERE, a videoaula é, geralmente, a primeira (e muitas vezes a única) metodologia que os professores optam por praticar. As muitas demandas impostas pelas escolas aos professores e as dificuldades inerentes à aplicação do ERE, fazem com que optemos por ofertar videoaulas ou textos aos estudantes, em uma espécie de "prontaentrega" de conteúdo, sem um pensar sobre a pedagogia subjacente ao processo ou sobre os possíveis impactos dessas práticas (FLORES; LIMA, 2021). Para nós, uma das razões para optarmos por produzir videoaulas é o fato de que as graduações em licenciatura, em geral, não oferecem formação específica em ensino à distância (EAD) ou ERE. Deste modo, quando nós, docentes, somos desafiados a atuar em tais modalidades, a videoaula se mostra como uma das possibilidades que mais se assemelham, com ressalvas, às aulas presenciais. Esta idéia é reforçada por uma pesquisa realizada em 2018 com 85 estudantes da ESEM que revelou que todos eles consomem videoaulas para estudar química. Segundo as autoras, os alunos utilizam este recurso para revisar $(54,8 \%)$, aprender $(27,4 \%)$ ou aprofundar $(12,3 \%)$ seus conhecimentos (SOUZA; SILVA, 2019). O comportamento dos participantes desta pesquisa provavelmente reflete a atitude de muitos jovens brasileiros que usam cotidianamente as redes sociais e sites repositórios de vídeos, como o YouTube®, para assistir videoaulas. O resultado foi um montante considerável de videoaulas depositadas na plataforma ESEM por professores de diferentes disciplinas, que deveriam ser assistidas pelos estudantes da escola semanalmente. 
A oferta de videoaulas como único recurso de aprendizagem em ERE desconsidera o fato de que os adolescentes precisam desenvolver uma série de perspectivas obtidas através de diferentes tipos de aprendizado, para aprimorar suas capacidades de resolução de problemas, tomada de decisões e habilidades (CERI, 2007; EVANS et al., 2007). Especialmente neste momento de ERE, em que as adversidades são muitas, é importante que não esqueçamos a natureza do trabalho realizado pelo professor. A docência se caracteriza como uma atividade complexa que desafia os envolvidos para se colocarem como sujeitos em processo de permanente aprendizagem, em que é requerido a disposição para a inovação, a indagação e a investigação sobre seu objeto de ação (CANTONI et al., 2021).

A partir desse aspecto, entendemos que, tanto na educação presencial quanto no ensino remoto, para que a aprendizagem seja significativa e o engajamento e a motivação dos estudantes sejam desenvolvidos e/ou conservados, é essencial que as experiências de aprendizagem sejam diversificadas periodicamente, adequadas aos conteúdos, habilidades e competências que se objetiva aprimorar, e levem em conta as especificidades e necessidades discentes.

Para garantir a diversificação de estratégias e contemplar também os estudantes que não possuem pacote de dados suficiente para assistir a uma grande quantidade de videoaulas, foram disponibilizados na plataforma da ESEM, além das videoaulas, materiais escritos (em formato PDF) abrangendo todo o conteúdo trabalhado nas mesmas. Percebemos, porém, que estes materiais escritos, mesmo enriquecidos com imagens, não estavam sendo suficientemente apreciados por nossos estudantes. Precisávamos então desenvolver uma metodologia para o ERE que fugisse da lógica das videoaulas e que, ao mesmo tempo, mantivesse o engajamento dos estudantes que não têm condições de assistir às mesmas. O objetivo foi, em última análise, criar uma metodologia de ERE que superasse a lógica predominante das videoaulas, diversificando as experiências de aprendizagem e atendendo os estudantes em suas múltiplas especificidades cognitivas, 
econômicas e sociais. Assim surgiu o PowerPoint ${ }^{\circledR}$ dialogado, que descreveremos a seguir.

\section{PERCURSO DE EXPERIÊNCIA}

O PowerPoint ${ }^{\circledR}$ dialogado consiste em um arquivo PowerPoint ${ }^{\circledR}$ desenvolvido especificamente para alunos que estão estudando sem a presença física de seus professores. Como em qualquer outra atividade pedagógica, o primeiro passo para desenvolver um PowerPoint ${ }^{\circledR}$ dialogado é o planejamento, que deve considerar alguns pontos: as competências e habilidades a serem desenvolvidas e os conteúdos através dos quais elas serão trabalhadas; definição da ordem e da forma como cada assunto será distribuído nos slides (com animação ou sem); seleção e definição da ordem e localização em que serão apresentados imagens, gifs e pequenos vídeos ilustrativos; escolha dos tipos de balões de fala, caixas de texto e setas indicativas e definição da ordem e localização em que serão apresentados nos slides, além da triagem de materiais complementares e links a serem sugeridos como aprofundamentos dos estudos (não obrigatório).

É importante destacar que as intencionalidades pedagógicas (NEGRI, 2016) que embasam a construção de uma apresentação convencional de PowerPoint ${ }^{\circledR}$ (aplicado em aulas presenciais) não são as mesmas que alicerçam a elaboração do PowerPoint ${ }^{\circledR}$ dialogado. O PowerPoint $\AA$ dialogado se diferencia de uma apresentação de PowerPoint ${ }^{\circledR}$ convencional e de outros materiais que usualmente disponibilizamos aos alunos em ERE nos seguintes aspectos: é idealmente enviado ao aluno no modo apresentação de slides de PowerPoint ${ }^{\circledR}$ (*.ppsx), para que ele acesse cada slide, caixa de texto, imagem ou gif na ordem que o professor planejou, a partir de seus objetivos pedagógicos; contém animações que exibem ou escondem informações escritas ou imagéticas em momentos definidos pelo professor, além de dar dinamismo à apresentação; apresenta avatares das professoras, gerando um sentimento de familiaridade e acolhimento aos estudantes; pode conter links para materiais de estudo complementar (capítulos de livro, websites, reportagens, artigos, vídeos, simuladores, etc); pode conter instruções de uso do próprio PowerPoint ${ }^{\circledR}$ dialogado fornecidas pelo professor aos seus alunos; personaliza os tempos 
de aprendizagem (cada aluno estuda o material durante o tempo que precisar/desejar, podendo avançar ou retornar aos slides conforme seu interesse ou necessidade); apresenta linguagem coloquial, como se o docente estivesse conversando com os estudantes, e pode ser baixado com consumo de pequena quantidade de dados de internet. As figuras 1 a 4 apresentam alguns dos slides de determinados PowerPoint $\AA$ dialogados que foram produzidos e disponibilizados aos estudantes da $2^{\text {a }}$ série do Ensino Médio (E.M.) da ESEM no ERE de Biologia. As legendas especificam as características de cada slide que contribuem para que esta metodologia diversifique as experiências de aprendizagem significativa dos discentes.
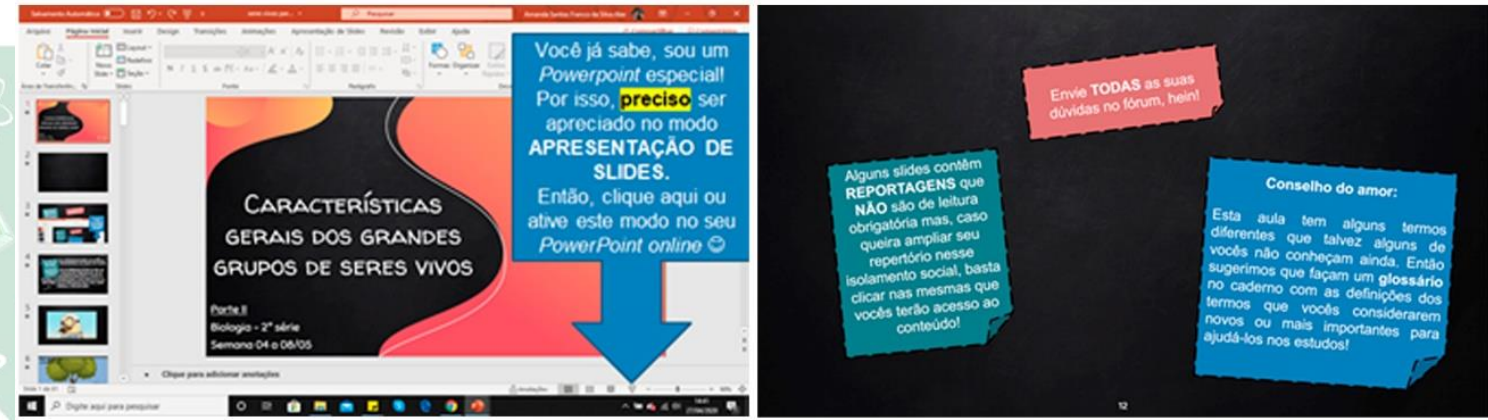

Figura 1: Esquerda: Instruções do próprio PowerPoint ${ }^{\circledR}$ dialogado para o aluno estudar no MODO APRESENTAÇÃO de slides, caso ele não tenha recebido o arquivo já neste modo. Direita: Exemplo de slide para estimular os estudantes a enviarem suas dúvidas e fazerem seus registros.
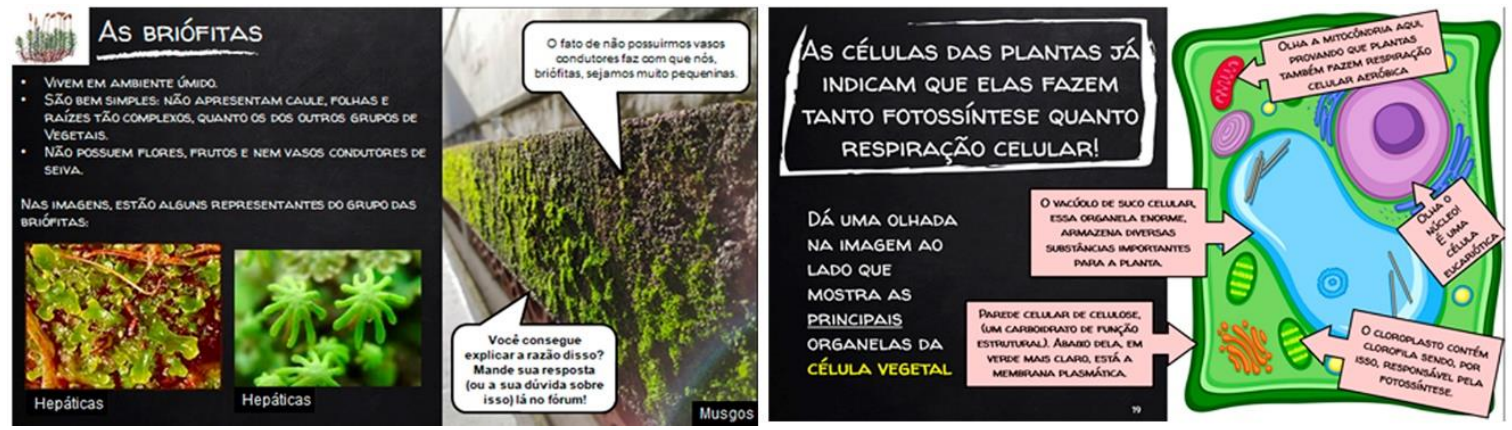

Figura 2: Esquerda: Slide com pergunta aos alunos para estimulá-los a interagir na plataforma Moodle®. Observe a personificação: os seres vivos apresentam balões de fala, como se estivessem conversando com os estudantes. Direita: Slide apresentando o uso de balões de fala (em rosa) indicando regiões específicas da imagem. A linguagem coloquial e a ordem em que os balões aparecem são definidas pelas professoras de acordo com suas intencionalidades pedagógicas. 

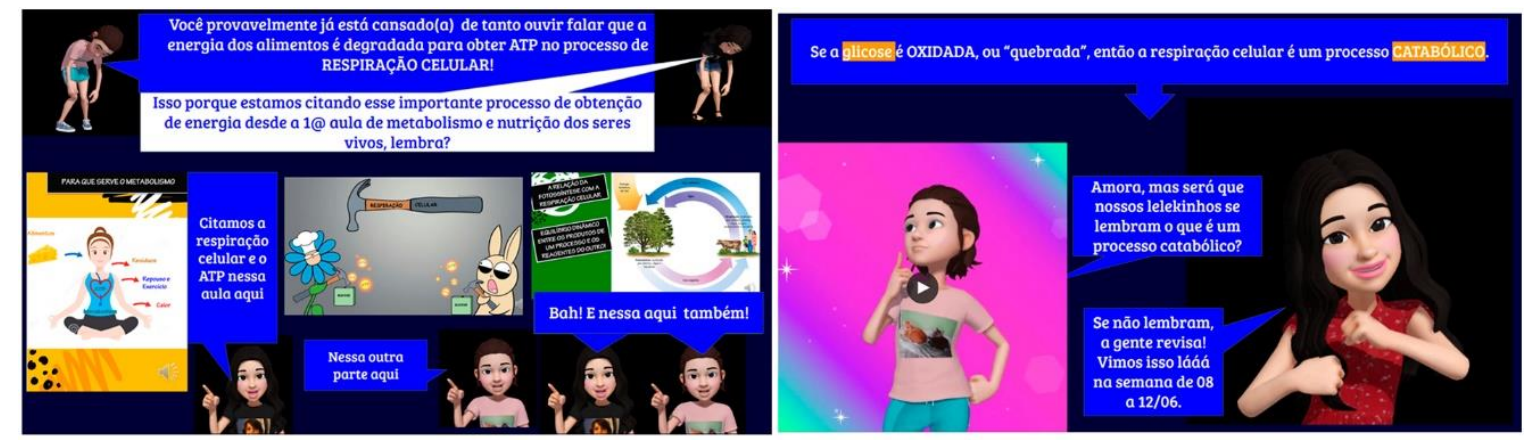

Figura 3: Esquerda: Slide introdutório do PowerPoint ${ }^{\circledR}$ dialogado revisitando conteúdos trabalhados anteriormente; cada imagem aparece após um clique do estudante. Direita: Slide em que os avatares das professoras "dialogam" com os estudantes, como fariam se estivessem em classe.
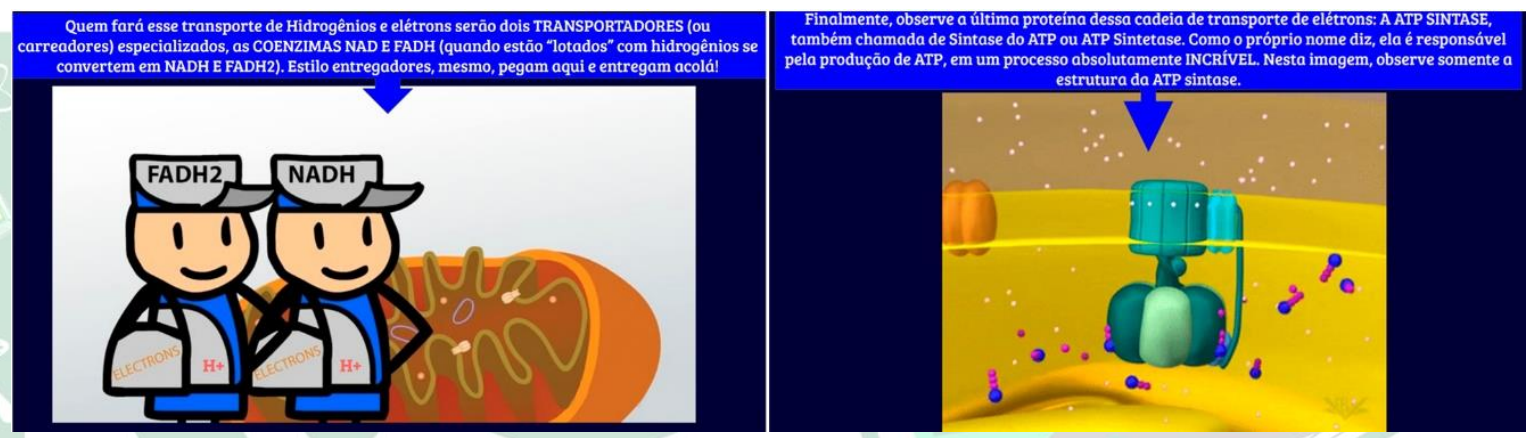

Figura 4: Esquerda: exemplo de slide com linguagem coloquial. Direita: Exemplo de slide apresentando imagem interativa, em formato GIF.

Para avaliar a eficácia da metodologia PowerPoint ${ }^{\circledR}$ dialogado na aprendizagem dos estudantes, em cada semana que a metodologia era aplicada era realizada uma avaliação convencional de conteúdo, a partir de um questionário com questões objetivas ou a produção de um mapa mental e uma autoavaliação denominada “Tudo OK?" (figura 5), através da qual os alunos revisitavam os objetivos iniciais de aprendizagem e assinalaram os tópicos que compreenderam plenamente. Propusemos ainda aos estudantes uma pesquisa de opinião ou preferência com base em quatro metodologias de ERE: PowerPoint ${ }^{\circledR}$ dialogado, videoaula, podcast ou texto. 


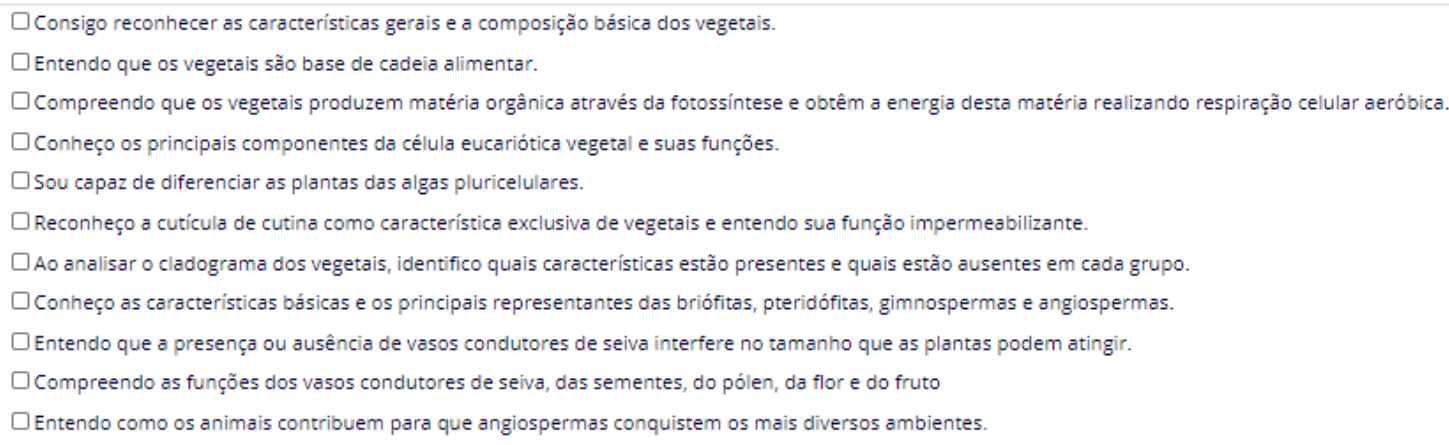

Figura 5: Exemplo de uma autoavaliação “Tudo OK?”. Os alunos são estimulados a assinalarem as opções que apresentam tópicos do conteúdo que eles consideram ter compreendido integralmente.

\section{DESDOBRAMENTOS DA EXPERIÊNCIA}

A aplicação da metodologia de ERE PowerPoint ${ }^{\circledR}$ dialogado gerou impactos social, pedagógico e emocional nos discentes. O impacto social se refere ao fato de que estudantes com pouco acesso à internet, com pacote de dados reduzido, conseguiram acessar o material e apreciá-lo como todos os outros alunos. No que tange ao impacto pedagógico, evidenciamos que a aprendizagem foi significativa ao analisarmos as respostas dos estudantes na autoavaliação “Tudo OK?” e na avaliação de conteúdos, resultados que serão descritos na seção a seguir. Também apresentaremos alguns dos comentários que recebemos dos estudantes, nos quais eles afirmam que ao estudarem com o PowerPoint ${ }^{\circledR}$ dialogado sentem-se "em sala de aula" com suas professoras, além de se divertirem com os memes e outras ferramentas aplicadas na metodologia. Esta sensação de familiaridade e acolhimento relatada pelos estudantes foi o que constatamos como o principal impacto emocional da metodologia.

\section{PRINCIPAIS RESULTADOS ALCANÇADOS}

Durante as semanas de aplicação do PowerPoint ${ }^{\circledR}$ dialogado verificou-se que todos os estudantes puderam ter acesso ao material ofertado, independentemente de seus pacotes de dados de internet. Além disso, na autoavaliação "Tudo OK?" a maioria dos 
estudantes respondeu que todos os objetivos de aprendizagem foram alcançados (figura

$6)$.

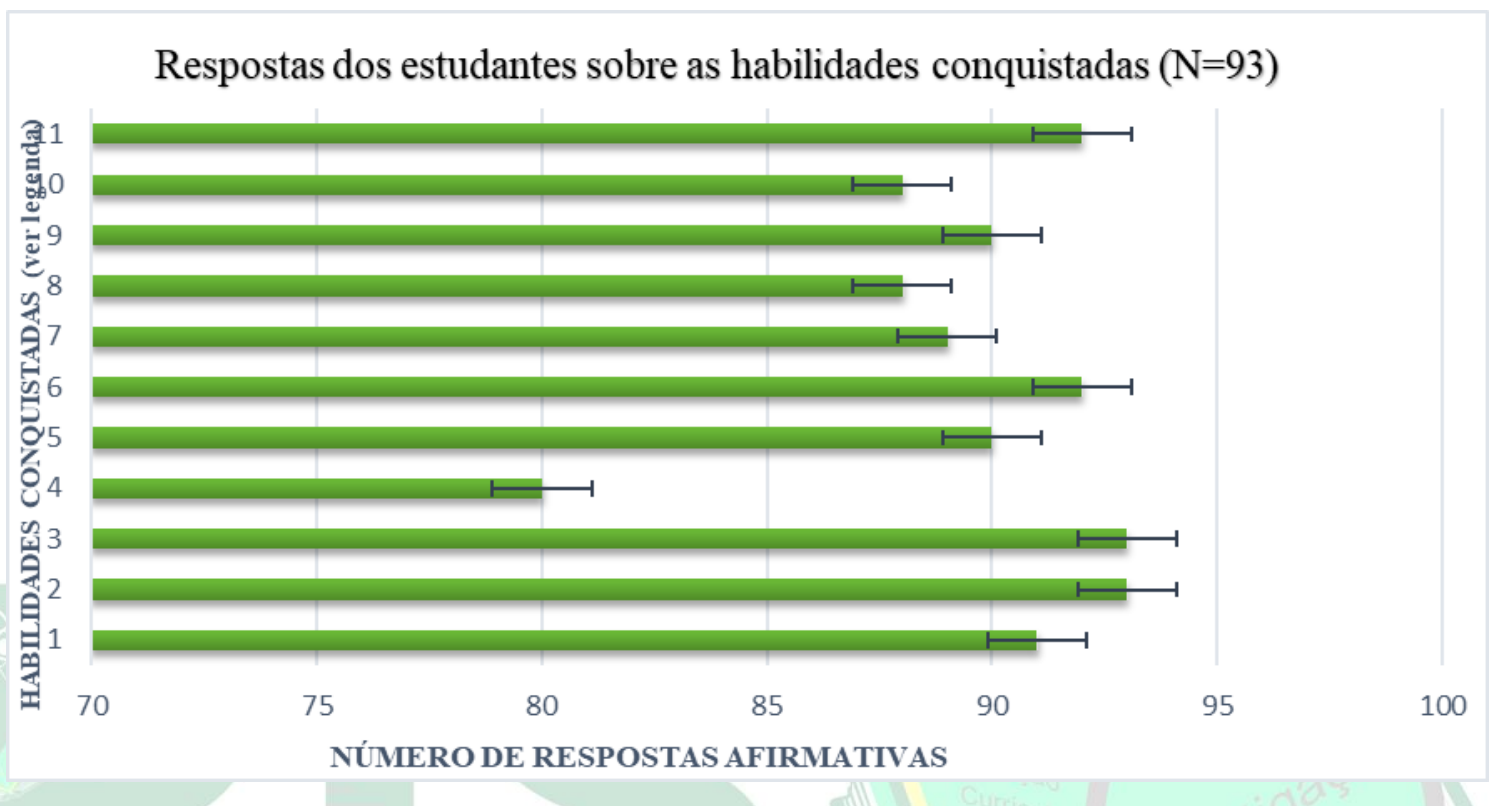

Figura 6: Resultado de uma das autoavaliações “Tudo OK?" realizada com os estudantes após estudarem através do PowerPoint ${ }^{\circledR}$ dialogado. A maioria dos estudantes respondentes assinalou que "compreendeu integralmente" quase todos os tópicos trabalhados. Legenda das habilidades trabalhadas: 1- Consigo reconhecer as características gerais e a composição básica dos vegetais. 2- Entendo que os vegetais são base de cadeia alimentar.3Compreendo que os vegetais produzem matéria orgânica através da fotossíntese e obtêm a energia desta matéria realizando respiração celular aeróbica. 4- Conheço os principais componentes da célula eucariótica vegetal e suas funções.5- Sou capaz de diferenciar as plantas das algas pluricelulares.6- Reconheço a cutícula de cutina como característica exclusiva de vegetais e entendo sua função impermeabilizante.7- Ao analisar o cladograma dos vegetais, identifico quais características estão presentes e quais estão ausentes em cada grupo. 8- Conheço as características básicas e os principais representantes das briófitas, pteridófitas, gimnospermas e angiospermas. 9- Entendo que a presença ou ausência de vasos condutores de seiva interfere no tamanho que as plantas podem atingir.10- Compreendo as funções dos vasos condutores de seiva, das sementes, do pólen, da flor e do fruto. 11-Entendo como os animais contribuem para que angiospermas conquistem os mais diversos ambientes.

Na pesquisa de opinião, 51,58\% dos estudantes elegeu o PowerPoint ${ }^{\circledR}$ dialogado como o melhor material para estudar biologia, dentre as quatro metodologias ofertadas durante o ERE, enquanto 46,32\% preferiram as videoaulas (figura 7). Cabe salientar que não houve indicação de preferência por materiais textuais ou podcasts. 


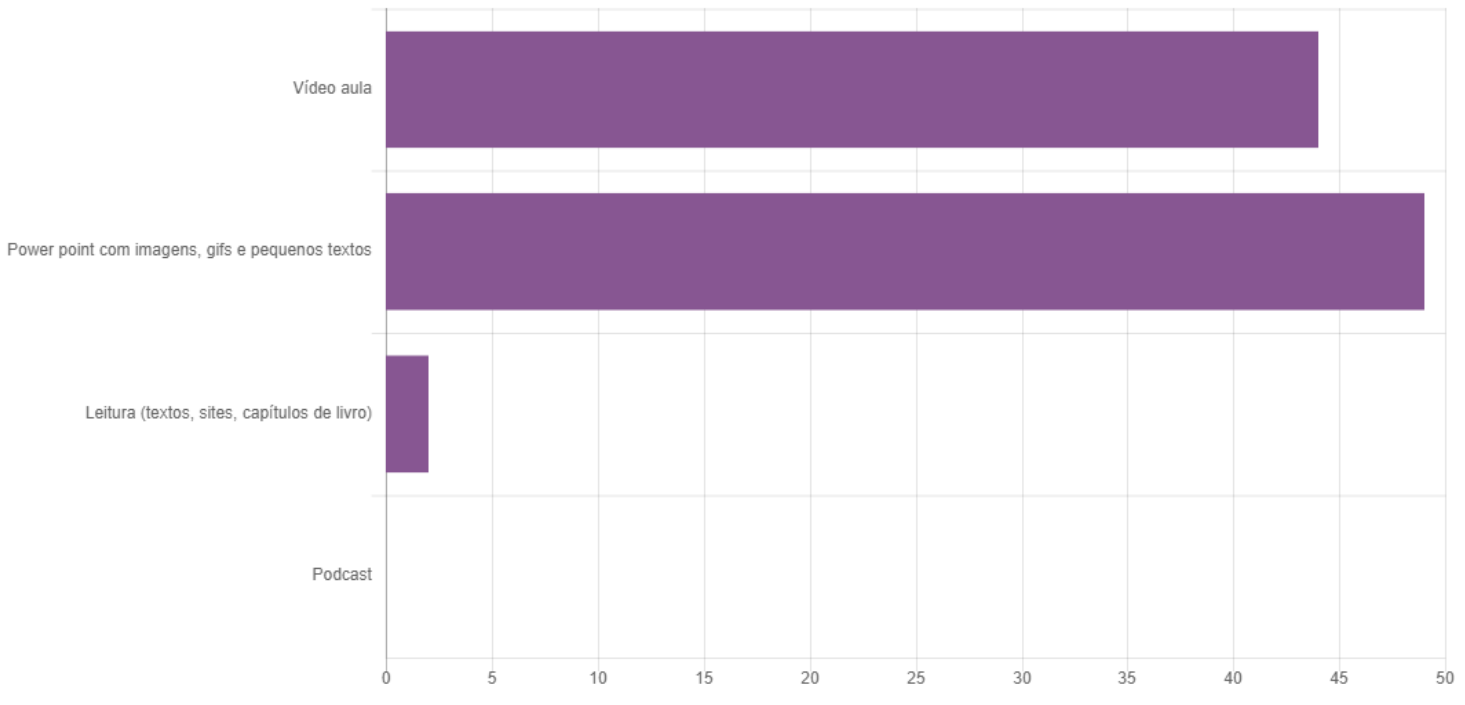

Figura 7: Das quatro alternativas de materiais ofertadas ao longo das oito semanas de ERE, nenhum dos 95 alunos respondentes teve preferência por podcasts e 2,11\% preferem materiais textuais. 51,58\% dos estudantes elegeram o PowerPoint ${ }^{\circledR}$ dialogado como material ideal para estudar Biologia, enquanto $46,32 \%$ optaram por videoaulas.

Recebemos depoimentos dos estudantes elogiando a nova metodologia, sentindose acolhidos e manifestando que pareciam estar na presença das professoras em sala de aula. Abaixo, transcrevemos alguns deles:

Estudante 1: "Não posso terminar esse e-email sem elogiar os slides de bio dessa semana, ARRASOUUUU. Dava p sentir vc e a Quijada lendo aquilo kakkkakkak, tava tão fofinho q ficou menos cansativo, inclusive adorei as piadinhas." (sic).

Estudante 2: "Amandinha e Carlinha, os slides estão perfeitos, eu amei..." (sic).

Estudante 3: “... faço as matérias de Bio com muita dedicação, isso é facilitado pelos motivos de a matéria ser minha favorita e ter as melhores professoras e os melhores slides." (sic).

Estudante 4: "Apesar de levar um tempo para me acostumar com a plataforma escolar, creio que absorvi bem todo o conteúdo aplicado neste trimestre. O fato de Biologia ser a minha matéria favorita facilitou o 
aprendizado, além disso, creio que as aulas feitas pelas Amoras me ajudaram muito, já que eram objetivas e claras”. (sic).

Nas avaliações de conteúdo, a média das notas dos estudantes foram 8,52 no questionário e 9,19 no mapa mental.

A seguir, disponibilizamos links para apreciação dos PowerPoint ${ }^{\circledR}$ dialogados que desenvolvemos no ano de 2020, na disciplina de Biologia, para turmas do $2^{\circ}$ ano do E.M. da ESEM, distribuídos por assunto:

- Características gerais dos grandes grupos de seres vivos - PARTE I: https://escolasescmy.sharepoint.com/:p:/g/personal/aabe_escolasesc_com_br/EVXZ4mIpYS9Ghp N6rLAoAJUBeL-89gMBiJEw5Rtbueoc4g?e=H8hFmU

- Características gerais dos grandes grupos de seres vivos - PARTE II: https://escolasesc-

my.sharepoint.com/:p:/g/personal/aabe_escolasesc_com_br/EWet_s0ixeNLnMH $\underline{\text { Xus9iNGEBrPbohwsFmS28uWmZesSfuw? }=\text { m6mQNE }}$

- Metabolismo e nutrição parte III: https://escolasescmy.sharepoint.com/:p:/g/personal/cquijada_escolasesc_com_br/EeUgulQq-31FjgQT3SdA1IBhtO4iNY7RXzTr21rMmJJoA?e=VfE8He

- Transportes através da membrana plasmática: https://docs.google.com/presentation/d/1L2eTSw7vMcDs9WWb9CGPvPQ6xK oTPYlNhF1uQX9nQsQ/edit?usp=sharing

- Circulação de substâncias nos animais: https://docs.google.com/presentation/d/18ZqVMwKZOtHEhy6NOLJA2jW67f4 sbOXLVKSkZEXSIg4/edit?usp=sharing 
- Sistema linfático:

https://docs.google.com/presentation/d/1i1Idk_e1SAvQtkeZBSoOBQWrsTbZ1 Bib5j2fHSXFyeQ/edit?usp=sharing

- Trocas gasosas nos animais:

https://docs.google.com/presentation/d/1iRLLz35MYkFFCEdURymNL358FGf a2J8W x6Wsy2iVvY/edit?usp=sharing

- Respiração celular aeróbica:

https://docs.google.com/presentation/d/1038PPSN9Q7klYxxZDKBT8IIl_xnwQ 9Emw6Xzxh3A70Y/edit?usp=sharing

\section{CONSIDERAÇÕES FINAIS}

A nova metodologia criada demonstrou ser um material eficaz para a aprendizagem de biologia durante o ERE. Dentre os fatores que contribuíram para que essa iniciativa fosse bem sucedida estão: a produção dos slides de PowerPoint ${ }^{\circledR}$ de maneira diferenciada com relação aos slides que geralmente desenvolvemos para as aulas presenciais; o acolhimento aos alunos promovido pela linguagem coloquial e dialogada e pelos avatares da professoras; o dinamismo da aula graças aos gifs, aos questionamentos e às imagens, animações e setas explicativas; a inclusão promovida pelo fato de que todos os estudantes puderam acessar o material, independentemente do seu pacote de dados de internet e, finalmente, graças à preferência demonstrada pelos estudantes por essa metodologia de ERE. 


\section{REFERÊNCIAS}

AMARAL, M. A.; ASSIS, K. K.; BARROS, G. C. Avaliação na EAD: contextualizando uma experiência do uso de instrumentos com vistas à aprendizagem. IX Congresso Nacional de Educação - EDUCERE. III Encontro Sul Brasileiro de Psicopedagogia. 26 a 29 de outubro de 2009.PUCPR. Curitiba-PR, 2009.

CANTONI, J.; ROCHEMBACH, E. S.; CHIAPINOTO, M. L.; LAUXEN, A. A. Estágio Curricular Supervisionado: perspectivas e desafios de constituir-se educador em tempos de pandemia. Revista Insignare Scientia. V. 4, n. 3, p. $369-$ 385, 2021. DOI: https://doi.org/10.36661/2595-4520.2021v4i3.12130 Centre for Educational Research and Innovation (CERI). Understanding the Brain: the birth of a learning science. Paris: Organization for Economic Cooperation and Development. 2007.

EVANS, K., GERLACH, C. \& KELNER, S. The Brain and Learning in Adolescence, in CERI (Ed.) Understanding the Brain: the birth of a learning science, 186-210. Paris: Organization for Economic Cooperation and Development. 2007.

FLORES, J. B.; LIMA, V. M. R. Educação em tempos de pandemia: dificuldades e oportunidades para os professores de ciências e matemática da educação básica na rede pública do Rio Grande do Sul. Revista Insignare Scientia. V. 4, n. 3, p. 94 - 109, 2021. DOI: https://doi.org/10.36661/2595-4520.2021v4i4.12116

HODGES, C.; MOORE, S.; LOCKEE, B.; TRUST, T.; BOND, A. The Difference Between Emergency Remote Teaching and Online Learning. EDUCAUSE REVIEW, 2020. Disponível em https://er.educause.edu/articles/2020/3/the-differencebetween-emergency-remote-teaching-and-online-learning. Acessado em 25/05/2020.

MORAN, J. M. A educação que desejamos: novos desafios e como chegar lá. 2. ed. Campinas, SP: Papirus, 2007. 174p.

NEGRI, P. S. (org.). A intencionalidade pedagógica como estratégia de ensino mediada pelo uso das tecnologias em sala de aula. Londrina: Labted, 2016. Disponível em https://www.labted.net/single-post/2016/05/30/ARTIGO-AINTENCIONALIDADE-PEDAG\%C3\%93GICA-COMO-ESTRAT\%C3\%89GIA-DEENSINO-MEDIADA-PELO-USO-DAS-TECNOLOGIAS-EM-SALA-DE-AULA-1. Acessado em 27/05/2020.

SOUZA, D. P. B.; \& SILVA, G. C. S. Como os estudantes fazem uso do recurso didático das videoaulas na aprendizagem de química. Resumo publicado nos anais do VII Congresso Brasileiro de Educação, 2019. Disponível em 
http://cbe.fc.unesp.br/cbe2019/anais/index.php?t=RE2019033130084\#. Acessado em 25/05/2020.

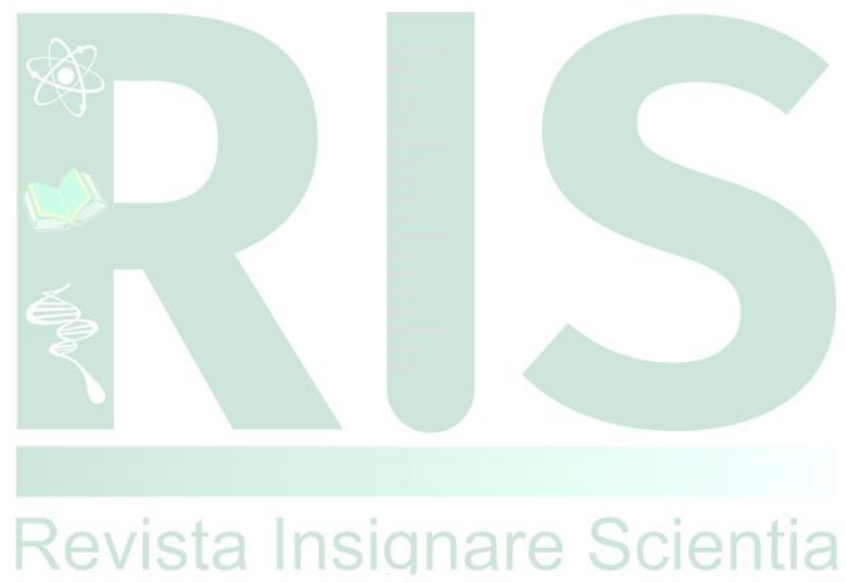

